\title{
Administration in the Operating Room
}

\author{
Tagarakis A. Ioannis \\ Postgraduate Master's Degree Program, Health and Social Care Services Management, \\ Aristotle University of Thessaloniki, Greece \\ E-mail: tagio1998@gmail.com
}

Tsiapourlianos K. Panagiotis

Postgraduate Master's Degree Program, Health and Social Care Services Management, Aristotle University of Thessaloniki, Greece

E-mail: panagiotistsiapourlianos@gmail.com

\begin{abstract}
Valentina Vaxevani
Postgraduate Master's Degree Program, Health and Social Care Services Management, Aristotle University of Thessaloniki, Greece

E-mail: valentina091@hotmail.com
\end{abstract}

Tsolaki Fani

Postgraduate Master's Degree Program, Health and Social Care Services Management, Aristotle University of Thessaloniki, Greece

E-mail: fantsolaki@icloud.com

Karakolias Stefanos

Postgraduate Master's Degree Program, Health and Social Care Services Management, Aristotle University of Thessaloniki, Greece

E-mail: skarakolias@gmail.com

\section{Tagarakis I. Georgios}

Postgraduate Master's Degree Program, Health and Social Care Services Management, Aristotle University of Thessaloniki, Greece E-mail: gtagarakis@gmail.com 


\title{
Macrothink
}

Received: Dec. 27, 2021 Accepted: Feb. 2, 2022 Published: March 6, 2022

doi:10.5296/ijssr.v10i1.19635ＵRL: https://doi.org/10.5296/ijssr.v10i1.19635

\begin{abstract}
When referring to the operating room of a health organization, we know in advance that it is a department that is accompanied by multiple requirements and high responsibilities from all the human resources that staff it. Its high demands and great responsibilities result, on the one hand, from the criticality of the state of health of each patient and from the special characteristics that accompany it, from the existing risk of complications during the operation, and on the other hand, from the diversity from which characterizes the team of human resources that staffs the operating room. More specifically, the operating room consists of the director, the head, the head of the department, the medical staff, the nursing staff, the technical department and the administrative department. The medical department is divided into the competent surgeons and anesthesiologists. The smooth operation of this department requires effective cooperation and communication between all members of the surgical team. Clear definition of roles and responsibilities plays a key role in avoiding unwanted conflicts between surgeons, anesthesiologists and nurses. The director and the head of the operating room, as well as the head of the department, play a leading role in avoiding these conflicts. For this reason, these jobs must be staffed by employees who, in addition to technical skills, have administrative and communication skills. The wider part of the operating room of a health organization should be staffed by health professionals who have increased experience in their specialty and have all the necessary knowledge, in order to make a proper preoperative assessment of the patient's health condition and timely and effective anticipation and treatment problems that may arise during the surgical procedure.
\end{abstract}

Keywords: surgery, administration, health organizations, health professionals 


\section{Introduction}

The ultimate purpose of this thesis is the study of the administrative part of the operating room and the description of the duties and responsibilities of the competent medical, administrative, nursing and other personnel, who are employed in these areas. The implementation of general rules and guidelines in surgical areas is a matter of utmost importance, for reasons of ensuring the smooth running of the surgical unit and the achievement of adequate operating and working conditions, on the one hand, for reasons of ensuring the required levels of safety and, on the other hand, for reasons of maximum productivity of the human resources employed.

The operating theatre is the specialized unit in which surgical procedures and other interventional medical activities are carried out, in which strict aseptic conditions are observed and in which the necessary general anesthesia is possible. The operating hours of the surgical units are governed by the legal form of the respective health institution, i.e., public or private law, as well as by the content of the operating contracts of the health organization and the employment contracts concluded with the staff employed. The operating theatres of each hospital unit shall include at least two operating theatres, one for aseptic cases and one for septic cases. They also include the pre-care area, the recovery area, the doctors' offices and the areas where the medical staff may rest. In addition to the above, the operating theatre area includes other ancillary areas, typical examples of which are the storage areas for stretchers and the materials required for surgery, toilets, the storage area for the dirty clothes of the staff working in the operating theatre and the sterilization areas. Finally, a fully equipped sterilization department is included, which contains all the necessary modern equipment needed in order to carry out adequate preparation before a surgical procedure. In this room all the necessary tools for each surgical procedure are kept.

The proper functioning of the operating room department is directly related to its administrative efficiency. For this reason, the present study is characterized as important and significant, given the seriousness and criticality of the procedures performed in the surgical rooms of hospitals.

\section{Literature Review/Methodology}

For the purpose of our research, we have reviewed a significant number of published studies. The literature on this topic was studied thoroughly in order to create and compile a scientific study around this major problem. Both from the international and domestic literature, important results could be drawn.

\section{Results and Findings}

Organization, not exclusively in the field of surgery but in the business world in general, is understood to mean a properly formulated plan, which reflects the relationships of cooperation between the people who hold various jobs in each department of an organization. This plan must be formally adhered to by all human resources and by all the individual departments of the organizations, to ensure that there are no deviations from it, as the proper functioning of the respective organization is undermined. 
The ultimate purpose of the organization and the formal plan of cooperation of the individual departments, reflected in the framework, is the best possible coordination of all the human resources of the organization, in order to ensure that the individual tasks to be carried out in the context of the exercise of the employees' professional duties are successfully covered. However, at this point, it should be noted that in order to achieve the best possible coordination of the actions and efforts of the human resources, it is necessary to have executives through whom the correct direction of the movements and actions of the rest of the human resources can be achieved. This coordination is promoted through key organizational factors. For the operating room in particular, leadership plays a key role.

The assignment of leadership is given to the head of the operating room department. Thus, the supervisor is responsible for determining the duties and job responsibilities of the employees in the operating room, while at the same time, he is responsible for fully understanding the duties and individual roles assigned to the specific workforce. On top of that, the supervisor is responsible for exercising control over the proper performance of all the necessary tasks that need to be completed. At this point, it is noted that it is particularly helpful to provide clear instructions in order to carry out all the necessary tasks consistently and efficiently. In addition, the promotion of teamwork is of particular importance in the effective execution of the required tasks. These are two additional points, which are assigned to the role played by the leadership, i.e., the head of the surgery. The main characteristics that help to achieve the desired results through effective coordination of the actions taken by the human resources, whose work is interwoven and relevant to the surgical area of an organization, are the following:

First of all, the repetition of a particular action by several workers at the same time should be avoided in any case. Thus, when there is proper coordination of the actions and actions required, each worker is able to know which actions to perform and when. It is particularly helpful, in this case, to be aware of the actions assigned to the other workers working together within a surgical team, in order to avoid the risk of repeating an action assigned to another member of the team. In the same logic, it is particularly important to avoid negligence and procedural errors when carrying out the required actions. This is another point where proper coordination plays a key role.

Equally important is the ability of the head of the surgery department to supervise and evaluate the results of each operation. In this context, there is also a proper allocation of roles, responsibilities and competencies to the individual members of the surgical team, who are required to work together to achieve the best possible outcome. In order to achieve the optimal assignment of roles and responsibilities to the individual members of the surgical unit by the supervisor, a prerequisite is the good knowledge of the skills and abilities of each member. In this way, the supervisor will be able to assign to each member of the surgical team the tasks and responsibilities that, in his or her judgment, can be carried out to the best extent, in accordance with their capabilities and abilities. Essentially, at this point, reference is made to the achievement of maximum work efficiency and effectiveness, which cannot be achieved without a good knowledge of the capabilities and abilities of human resources. The design of a specific job description is a prerequisite in order to achieve a clear distinction of 
roles, responsibilities and competencies of each member of the surgical team.

The last characteristic, which helps optimum coordination, is that of human resources satisfaction. Increased levels of job satisfaction are an additional important element that promotes and facilitates rational coordination on the part of the surgical department manager. The reason lies in the fact that when the members of the surgical team are satisfied with their working conditions, they are able to obey the orders they receive from the head of the department and perform the required actions accurately.

Given the above basic characteristics, which help the assignment of tasks to each member of the surgical team, from the point of view of the doctors and supervisors of the operating room, it is noted that it is equally important that each employee has knowledge of the collaborative relationships with the other members of the team. Similarly, each member of the surgical team should be aware of the collegial and collaborative relationships they should have with team members in other departments of a health care organization.

The basic functional plan of a health organization is defined by the organization and is reflected in a specific organization chart. On the side of this organizational chart, the individual hierarchical relationships are defined, as well as the individual service teams, the executive plans of the audit process and the existing levels of responsibility and leadership. It should be noted, moreover, that each member of the human resources of the health organization, and in particular of the operating theatre department, is accountable to the immediate superior. The hierarchical superior is authorized to give directions and orders to his/her subordinates. The exercise of administrative control and all the necessary guidance resulting from the results of such control may be achieved by issuing instructions. These instructions must be clear and specific and are given by those higher up in the hierarchy to those lower down the hierarchy. Thus, instructions are initially given by the hospital administrator, directed to the clinical directors, to the head of the department and then the instructions reach the rest of the human resources that make up the surgical team. In addition, it is even possible to reverse the attribution of responsibilities of the human resources employed in the surgical department, i.e., to assign responsibilities from the bottom up, based on the existing hierarchy reflected in the organizational chart of the department. In this case, accountability starts with the other human resources, which is composed of the members of the surgical team, is directed to the heads of the department, then to the clinical directors and finally to the hospital administrator.

Despite the fact that each service, or each department of a health organization, reflects an integral and individualized unit, which is a separate part of the whole, this does not imply differentiation and separation of its operation from the operation of the other departments. Typical examples of the individual departments that make up a health organization are the administrative, technical, medical, nursing and other similar departments. The alignment, combination and coordination of the operation of the individual independent departments is aimed at the optimal achievement of a common goal of the health organization. Thus, in this context, interdepartmental relations of work and cooperation are formed, which are not characterized as relations of power. 


\section{Macrothink

The operating room department of a health care organization is a separate department of that organization. Based on the existing administrative organization of the surgical department, the head nurse ends up reporting on his/her actions and activities to the head of the nursing department, as well as to the director of the surgical department. This is the case in most healthcare organizations but may vary depending on the regulation in force in each organization.

More specifically, the head nurse of the surgical department is responsible for the effective planning and rational management of the operation of the surgical department, with regard to nursing issues. The person who has that position is also responsible for the actions of the nursing workforce, as well as its leadership.

However, it is essential to note that on the one hand the tasks and on the other hand the power and cooperation relationships of the human resources employed in the operating room are differentiated according to the following characteristics, which are not identical in all health care organizations.

- The operating room department size

- The number of staff employed in the operating theatre department

- The grade carried by each member of the surgical team

- The responsibilities

- The degree of urgency of the situation arising

- The scheduling of work

- The way in which the work is carried out.

It is a fact that the surgical department reflects the most sensitive area of a health care organization. It is a department with specific and distinct purposes and a specific regulatory framework. In fact, the rules governing the surgical department are tending to expand as they are aligned with new prevailing conditions that are emerging on issues of health and care, technological advances and social reforms.

In order not to undermine the functional smoothness of the surgical department of a health care organization, many different factors must be addressed, which are directly related to the design architecture of the specific department on the one hand and the human resources employed in it on the other. Both the design of the department and the work of the human resources of the surgical department must be operated in such a way as to achieve an optimal relationship between effort and time, with the ultimate goal of providing the best possible service to the patient.

The operating room is the only department in healthcare organizations where the basic operating principles must be fully implemented with discipline, precision and rigor by the entire surgical team. This is an existing need, which becomes even more urgent in the context of modern times, due to the increased responsibilities of medicine. The urgency of the 
above-mentioned need is also justified by the rapid progress of technology, the expansive nature of automation, the expanding trend of interventions in the operating room, such as cardiac surgery, as well as the emergence of new diseases, such as AIDS and arthroplasty.

Moreover, following the mandatory alignment of national health legislation and the health organizations' terms of reference with the corresponding European ones, but also following the adoption of a specific legislative framework for the safeguarding of patients' rights, such as for example Law 2519/199732 and the provisions of Article 47 of Law 2071/199233, the responsibility for not deviating from the regulatory framework of the surgical department of the respective health organism acquires even greater substance.

At this point, it is clarified that a modern surgical room must necessarily be accompanied by the corresponding discipline of the human resources employed in it and be equipped with the most optimal equipment in order to successfully perform the necessary interventions. Particularly important is the observance of all the necessary hygiene rules, because the operating room must be free of infections and microbial contamination.

The operation of the operating theatre is achieved through the full composition of the human resources of the surgical team, during the regular legal working hours, during working days.

In the context of the general operation of the surgical area, it is essential to comply with the regulatory framework on issues of maintaining asepsis. This is a matter of utmost importance, as mentioned above, in order to comply with all hygiene and safety rules in the operating room and to avoid unwanted and dangerous infections. The rules of asepsis must be observed by all personnel involved in the surgical team. Thus, only the manpower required for the successful performance of the surgery should be present in the operating theatres. In fact, the staff present in the operating theatre must wear appropriate clothing, which promotes the maintenance of asepsis. The head of the operating theatre department, in collaboration with the surgical committee and in any case, in proportion to the existing needs of the individual departments, in the operating theatre and depending on the type of on-call duty of the health organization, must draw up a corresponding program. Changes to this program are possible, depending on the specialization of each health organization (e.g., oncology) and the number of cases that arise.

The director of the surgical department, with the primary objective of providing optimal patient care and the successful completion of surgical procedures within the required time frame, taking into account the exceptional nature of each case, its unseptic or non-septic nature, the existing training needs of the medical and nursing staff and the completeness of the health organization, with regard to the issue of hospitalization, draw up the so-called schedule of the operating department. The schedule of the department in the operating theatre must be communicated to the anesthesia department of the health organization and to the head of the department in question. The surgical schedule includes basic information, such as the patient's name, gender and age, the patient's ward, the diagnosis, the invasive procedure to be followed, the anesthesia to be applied, the hematological adequacy, as well as the details of the surgeon and his assistants. 
In order to achieve optimal coordination of the operating room schedule, the head of the operating room and the director of anesthesiology carry out a thorough review of the schedules of the individual departments they manage. This is a necessary procedure to determine whether the surgery can be carried out under the conditions described in the above-mentioned program.

In case of disagreements between the nurses of the anesthesia department and the nurses of the surgery department, these are settled by the medical directors. In the event that there is a change in the above-mentioned schedule of the operating room, then this can be carried out with the agreement of the director and the head of the operating room, as well as the director of the anesthesia department of the health organization. In the case of emergency surgery, the above-mentioned schedule of the surgical department must include provision for the maintenance of at least one empty operating room. This room may be made available for the treatment of emergencies or for cases of active on-call work of the health care organization. However, this does not imply that there is no risk of the absence of available operating theatres to deal with emergencies and incidents that arise during the organization's on-call hours. In any case, acute cases take precedence over planned surgical cases, in which case new operating rooms are not available, so that both acute and planned cases can be performed at the same time. In the above-mentioned emergencies, optimal coordination of the head of the surgical department and the physician in charge is required. If there is a disagreement between them, then it is resolved by the directors of the surgical and medical departments. However, even in the event of a disagreement between the directors of the two departments mentioned above, the final decision is taken by the director of the operating department. At this point, it is clarified that a competent doctor is the one who is able to characterize whether an incident is acute or not. Therefore, the responsible doctor can classify an incident as an emergency or non-emergency. There is then a similar validation by the director of the operating room department.

The anesthesiologist on duty is responsible for the process of assessing the patient's condition in order to administer the corresponding anesthesia. It is therefore up to the patient to decide on the type of anesthesia and the time at which it can be administered.

Issues regarding the availability of the operating room and the equipment required to perform the surgical process are the responsibility of the nurse in charge of the operating room department, once normal operating hours have ended.

Postponement of surgical processes is not allowed in cases of planned surgical procedures, in which the patient has already entered the process of preoperative preparation. They are permitted, only in certain exceptions.

Timely notification of the surgery department, in case of postponement of a scheduled surgery, becomes essential. This information procedure is the responsibility of the anesthesiologist on duty or the nurse in charge of the department where the patient is being treated.

With regard to the patient preparation stage, it is clarified that the competent physician is 
responsible for issues such as the updating and signing of the acceptance form of the surgical process, the performance of all necessary tests that are part of the preoperative control, the completion of the corresponding hospitalization sheet, the recording of all required instructions that must be followed during the preoperative preparation of the patient, as well as ensuring that the necessary amount of blood to be used in the transfusion process is available. The anesthesiologist is responsible for the preoperative visit of the patient and the assessment of the patient's condition before the start of surgery, as well as the performance of the preanesthesia procedure. The head of the surgical department is responsible for the execution of all the instructions required for the preparation of the patient for the surgical procedure on the one hand, and for the preparation of the patient on the other hand. Regarding the anesthesia of the patient, before the invasive procedure, the type and form of anesthesia is decided by the anesthesia department of the health care organization. Before any decision is made, the agreement of the responsible surgeon must be obtained. The surgeon-physician who is responsible for performing the surgery is responsible for checking and studying the patient's hospitalization sheet, as well as for performing pre-operative clinical and laboratory tests, as mentioned above. This is a procedure that must be followed in order for the surgeon to form a thorough opinion of the patient's condition before the surgical procedure begins.

Once the surgery is completed, the anesthesiologist in charge is responsible for deciding whether to move the patient to the recovery room and then to the department where the patient is being treated. The responsible paramedics of the operating theatre are responsible for the transfer of the patient from the surgical ward and the recovery room to the corresponding hospital department. However, as mentioned above, any such type of patient movement cannot be performed without the anesthesiologist's order.

Firstly, it is noted that the broader scientific and administrative responsibility for the operational coordination of the operating theatre lies with the director of the surgical department of the health organization. In order to analyze the responsibilities of the medical service, the following categories are highlighted and described:

In particular in the case of health organizations, which are characterized by their large size and have no more than twenty doctors working in the surgical department, it is necessary to set up a so-called surgical committee. This committee acts whenever necessary and plays the role of an auxiliary advisory body for the coordination and administrative processes of the Director of the Department of Surgery.

Thus, the operational framework of the surgical department is entrusted to the surgical committee, which is composed of three members, namely the director of the surgical department, or alternatively the deputy director, the director of the anesthesia department of the health organization, or alternatively the deputy director of the anesthesia department, the head of the surgical department, or alternatively the deputy head.

In fact, in cases of a specialized problem, it is necessary for the surgical committee to be completed by the chief surgeon, who is appointed to fill the specific position, by the scientific board of the health organization, and also by the agreement of the director of the surgical 
department.

The surgical committee is chaired by the head of the surgical department. In fact, the decisions taken by this committee must not deviate from the specific and broader directives of the health organization's operating rules. In addition, when the surgical committee meets, and depending on the nature and type of the problem arising, the participation of the director of the medical department of the health organization and the chairman of the scientific council may be allowed at these meetings. The broader issues of responsibilities or procedures followed by the surgical committee are described in the legislative provisions of Law 2519/1997.

More specifically, the responsibilities of the surgical committee include the supervision of the observance of the rules of medical ethics and the broader operational framework of the surgical department. Also, as part of its responsibilities, it is responsible for overseeing compliance with all the bureaucratic and formal procedures described in the previous chapter, which relate to the framework of a planned or emergency surgery.

The surgical committee is also responsible for the coordination, recommendation, allocation of operating rooms, the equipment required for the smooth conduct of the surgery and the number of operations required. These recommendations are aligned with the prevailing specific conditions, both in the health organization and in the surgical department in particular. These include issues of human resource availability, on-call work of the health care organization and other similar issues Finally, the surgical committee is responsible for assisting the head nurse of the surgical department in the preparation of the daily schedule of the operating room, other prevailing committees and the health organization, as well as the director of the surgical department, in matters of emergency response and management.

Anesthesia Department

This is a sector that comes under the surgical department of a health organization. The anesthesia department is staffed by the following human resources specialties:

- Technologists who are trained both in the use and the effective operation of the mechanical equipment necessary during patient anesthesia.

- Specialized scientific medical human resources, including both residents and qualified anesthesiologists .

- Nurses who are specially trained, both in nursing and in patient recovery.

The anesthesia department is managed by a medical director or his deputy. In special cases, the anesthesiology department is headed by the A' supervisor. However, in the latter case, the first attending physician must necessarily have the specialty of anesthesiologist.

The regulatory framework of the anesthesia department must be fully aligned and harmonized with the corresponding regulatory framework of the surgical department of the health organization.

The medical staff, who staff the surgical department of a healthcare organization, have the 
following obligations:

- Precise and strict adherence to working hours, so that no postponements of scheduled surgeries occur.

- Sending the schedules of their operations to the head of the surgical department, so as not to undermine the smooth scheduling of surgical procedures.

- Scheduling of surgical procedures in order of priority, according to the severity of the patient's condition, while septic surgery should not be performed at the beginning but at the end of the program, in order to avoid risks of infection and contamination.

- Preparation of the patient for surgery and conducting all required laboratory tests.

- Take care of the cash handling of outpatients.

- Timely examination of the patient from the anesthetic side.

- Completion of all required special forms before the surgical procedure begins.

- Timely notification of the head and director of the surgical department, in case of changes in the planned surgical procedures.

- In cases of surgical procedures, which subsequently require post-operative hospitalization in the ICU, the physicians in charge of the hospital must ensure that there are beds available for the patient's hospitalization.

At this point, it should be clarified that the nursing workforce employed in the surgical department of a healthcare organization includes nurses from various specialties and educational backgrounds. This is a necessary condition, due to the fact that the nursing staff of the surgical department is in direct cooperation with the doctors-surgeons and, on the other hand, is responsible for maintaining all the necessary operating and safety rules in the operating room. On top of that, the nurses who staff the operating room are on standby to provide all the necessary tools and resources to ensure that the surgical procedure is carried out effectively, for each patient's case. This readiness implies close collaboration, not only with the human resources staffing the team in the operating room, but also with the human resources of the other departments of the health care organization.

The hierarchical relationship that exists in the nursing workforce of the surgical team is directly related to the extent and size of the surgical department of the healthcare organization. If the surgical area is characterized by a large size, then the hierarchical structure of the nursing staff of the surgical team is as follows:

Hierarchically superior is the head nurse. Depending on the size of the surgical team, more than one nurse supervisor may be present. This is followed by the teaching nurse and the qualified nurses. Next come the student trainees, who come from recognized nursing schools. Next come the nurses, followed by the ward assistants in the next hierarchical scale. Immediately afterwards, the secretaries of the operating room department follow. Finally, the staff responsible for cleaning the operating theatre rooms. 
The head of the operating theatre department is responsible for controlling the work carried out by the nursing staff in the operating theatre department. This control concerns issues of patient care and the coverage of daily professional obligations. It is within the responsibility of the head of the surgical department to regulate the working hours to be observed by the nursing staff, in order not to leave the resulting needs of this department exposed. Also, following the regulatory framework governing a particular health organization, the head of the surgical department is responsible for the preparation of all the resources required for the smooth running of the surgical procedure and for the availability of operating theatres. The head of the surgical department is responsible even for matters of granting leave to the staff of the surgical department.

Additional tasks that fall under the responsibility of the head of the department of the operating theatre are the coordination of the proper functioning of this department with the doctors-surgeons, the anesthesiologists, the surgical nursing department, the human resources employed in the recovery room, the department responsible for central sterilization issues, the pharmacy, the pathology laboratories, the cleaning departments, the warehouse and supplies department, as well as the technical department. For this reason, in order to fill the position of the head of the surgical department, a strong spirit of cooperation and teamwork is required, not only among the members of the surgical team, but also with the human resources employed in all other departments of the health organization.

The head nurse of the surgical department has duties that vary between the different health care organizations and vary according to the existing regulatory framework and the size of the surgical department. However, the head nurse of the operating theatre is the direct assistant to the head of the department, especially on issues of work supervision, coordination, control, ensuring maximum efficiency of human resources and meeting the needs of the surgical sector, from the point of view of the nursing staff employed.

The duties of the teaching nurse of the surgical department include both the training and the orientation of the new human resources that are recruited and staffed in this department.

The duties of the registered nurse employed in the surgical department are to ensure the successful conduct of the surgical procedure and the overall smooth running of the surgical department. This is a highly responsible and demanding job. Besides, for this reason, in order to fill this position, the possession of a degree from a higher nursing school and the completion of specialized training in the field of surgical technique is required.

The tool donor must necessarily have completed specialized training for surgical technicians, which lasts about a year and takes place in hospital units or in specialized schools. The instrumentalist, in the exercise of his professional responsibilities, which fall within the scope of instrumentation during the surgical procedure, must fully apply the so-called aseptic technique. As part of their responsibilities, they are responsible for the adequacy of the required supplies, as well as for their cleanliness and sterilization.

Student nurses are trained for a period of approximately two months and in the event that it becomes necessary, an increase in the duration of training is not excluded. Their 
responsibilities include exclusively the learning of all the necessary nursing techniques, which are inherent to the surgical procedure, its smooth execution and the specific procedural issues, with which the surgical department of a health care organization is intertwined.

The secretary is a key member of the human resources that staff the surgery department. He is responsible for issues of daily routine and organization of the work required, for schedules of surgical interventions, for all the bureaucratic procedures that accompany the surgical procedure, for the receipt of the required supplies, for the maintenance of all the necessary evidence books and data, for ensuring the high level of patient care for the maintenance of all the necessary protocols, as well as for monitoring the movement of patient files between the individual departments of the hospital.

The human resources responsible for cleanliness issues in the operating theatre play an important role in ensuring the above-mentioned hygiene and cleanliness standards in the operating theatres. The exercise of the professional duties of these workers is important to avoid infections and contamination in the operating theatre.

The main tasks of the administrative department of the surgery department are the management of the financial budget of this department. This task is directly related to the rational and efficient management of materials, which are necessary for the smooth running of the department and the effective completion of surgical procedures. This requires accurate forecasts and effective preparation of the annual financial budget. In these procedures, the financial service of the health organization is particularly helpful.

The head of the surgical department also plays an important role in the above-mentioned process, at a time when he or she must be able to determine the approximate quantities of materials used by the surgical department and the costs involved in the use of these materials. In this process, the auxiliary role of doctors-surgeons, but also of the financial and management departments of the health organization is important.

Thus, the financial budget of the operating theatre department includes costs relating to the materials used during surgical procedures, spare parts for the equipment used in operations and other devices, repair and maintenance costs, operating costs, cleaning, sterilization, feeding, patient care, administrative costs, as well as costs relating to the salaries of the staff employed in the operating theatre human resources in this department.

At this point, it should be noted that the budget of the operating room department is divided into two categories, namely the budget for operating costs and the budget for the supply of the resources required to carry out the surgical procedures and interventions.

The exclusive responsibility of the technical service, which is independent but equal to the other services of the surgical sector of a health organization, is the permanent supervision, the strict control of the efficient operation and maintenance of all fixed and electrical installations located in the operating rooms. The technical service of the surgical department of a health care organization is divided into the technical department and the biomedical technology department. In the case of the technical department, the individual responsibilities and tasks are set out in the strict regulatory framework governing the health organization concerned. In 
general, the technical department is responsible for the execution and planning of all necessary development actions, as well as all necessary maintenance and optimization of the mechanical and building facilities of the operating room. The responsibilities of the technical department include the fire safety of the health organization.

The responsibilities of the Department of Biomedicine include the maintenance of all medical equipment, as well as all repair and control actions for the effective and successful operation of this mechanical equipment. In fact, the exclusive responsibility of the biomedical department is the drafting, in cooperation with the operators of the medical equipment, of all the necessary specifications, as well as the recommendation to the board of directors of the health organization for the procurement of new mechanical equipment where necessary.

\section{Conclusion and Recommendations}

Undoubtedly, the operating room area of hospital units is reflected by particularly demanding working conditions, which place a burden on the human resources that staff the surgical team. These aggravating working conditions are prevalent, on the one hand, because of the seriousness and criticality of the patients' health and, on the other hand, because of the multidimensional nature and type of health professionals who make up the above-mentioned surgical team.

As it became clear from the above analysis, the size of the surgical department team of a health care organization depends on the size of the health care organization on the one hand and on the other hand on its specialization. A surgical department consists of the director, the head, the head of the department, the medical department, which consists of medical surgeons and anesthesiologists, the nursing department, the administrative department and the technical department. Each of the above-mentioned departments has its own individual role and responsibilities, which must in any case be clearly and strictly separated from each other. The roles, duties and responsibilities of each job in the surgical department must be strictly defined by the operating regulations of the health care organization.

However, problems of controversy and internal conflicts cannot be avoided between specific subgroups of the surgical team. The most common cases of confrontations and conflicts are between doctors and nurses and between doctors-surgeons and anesthetists. Central to the effective management of these conflicts are the positions of the directors and heads of the surgery department and the position of the section chief. For this reason, these jobs must be staffed by employees who, in addition to the technical skills and the required knowledge background that is necessary, must be characterized by optimal communication, management and collaborative skills.

Finally, the staffing of the surgical team with specialized and well-trained human resources, in all the specialties from which it is composed, is considered particularly important and imperative, in order to be able to predict possible complications during the surgical procedure. The medical human resources of the surgical team play an important role in this respect, on which, in addition, the correct assessment of the patient's health status before the start of the surgical procedure depends. 


\section{References}

Ackroyd, R., Mouiel, J., Chevallier, J.-M., \& Daoud, F. (2006). Cost-Effectiveness and Budget Impact of Obesity Surgery in Patients with Type-2 Diabetes in Three European Countries. Obesity Surgery, $\quad 16(11), \quad 1488-1503$. https://doi.org/10.1381/096089206778870067

Adedeji, S., Sokol, D. K., Palser, T., \& McKneally, M. (2009). Ethics of Surgical Complications. Wournal of $\quad$ Surgery, 33(4), 737. https://doi.org/10.1007/s00268-008-9907-z

Agrusa, A., Frazzetta, G., Chianetta, D., Di Giovanni, S., Gulotta, L., Di Buno, G., \& Gulotta, G. (2015). "Relaparoscopic" management of surgical complications: The experience of an Emergency Center. Surgical Endoscopy, 30(7), 2804-2810. https://doi.org/10.1007/s00464-015-4558-2

Attri, J. P., Sandhu, G. K., Mohan, B., Bala, N., Sandhu, K. S., \& Bansal, L. (2015). Conflicts in operating room: Focus on causes and resolution. Saudi journal of anaesthesia, 9(4), 457-463. https://doi.org/10.4103/1658-354X.159476

Aufegger, L., Shariq, O., Bicknell, C., Ashrafian, H., \& Darzi, A. (2019). Can shared leadership enhance clinical team management? A systematic review. Leadership in Health Services, 32(2), 309-335. https://doi.org/10.1108/LHS-06-2018-0033

Başoğul, C., \& Özgür, G. (2016). Role of Emotional Intelligence in Conflict Management Strategies of Nurses. Asian Nursing Research, 10(3), 228-233. https://doi.org/10.1016/j.anr.2016.07.002

Beliaën, J., \& Demeulemeester, E. (2007). Building cyclic master surgery schedules with leveled resulting bed occupancy. European Journal of Operational Research, 176, 1185-1204. https://doi.org/10.1016/j.ejor.2005.06.063

Cardoen, B., Demeulemeester, E., \& Beliaën, J. (2010). Operating room planning and scheduling: A literature review. European Journal of Operational Research, 201, 921-932. https://doi.org/10.1016/j.ejor.2009.04.011

Cassera, M. A., Zheng, B., Martinec, D. V., Dunst, C. M., \& Swanström, L. L. (2009). Surgical time independently affected by surgical team size. American Journal of Surgery, 198, 216-222. https://doi.org/10.1016/j.amjsurg.2008.10.016

Catchpole, K., Mishra, A., Handa, A., \& McCulloch, P. (2008). Teamwork and Error in the Operating Room. Annals of Surgery, 247(4), 699-706. https://doi.org/10.1097/SLA.0b013e3181642ec8

Chang, D.-S., Leu, J.-D., Wang, W.-S., \& Chen, Y.-C. (2018). Improving waiting time for surgical rooms using workflow and the six-sigma method. Total Quality Management \& Business Excellence, 1-18.

Cooper, J. B. (2018). Critical Role of the Surgeon-Anesthesiologist Relationship for Patient 
Safety. Anesthesiology, 129(3), 402-405. https://doi.org/10.1097/ALN.0000000000002324

Dexter, F., Epstein, R. H., Traub, R. D., \& Xiao, Y. (2004). Making Management Decisions on the Day of Surgery Based on Operating Room Efficiency and Patient Waiting Times. Anesthesiology, 1444-1453. https://doi.org/10.1097/00000542-200412000-00027

Dimick, J. B., Pronovost, P. J., Cowan, J. A., \& Lipsett, P. A. (2003). Complications and costs after high-risk surgery: where should we focus quality improvement initiatives? Journal of the American College of Surgeons, 196(5), 671-678. https://doi.org/10.1016/S1072-7515(03)00122-4

El-Jardali, F., Tchaghchagian, V., \& Jamal, D. (2009). Assessment of human resources management practices in Lebanese hospitals. Human Resources for Health, 7(1). https://doi.org/10.1186/1478-4491-7-84

Erdogan, S. A., \& Denton, B. T. (2011). Surgery Planning and Scheduling. Wiley Encyclopedia of Operations Research and Management Science, 1-13. https://doi.org/10.1002/9780470400531.eorms0861

Ferris, G. (1999). Human resources management: Some new directions. Journal of Management, 25(3), 385-415. https://doi.org/10.1177/014920639902500306

Finlayson, S. R. G., \& Birkmeyer, J. D. (1998). Cost-effectiveness analysis in surgery. Surgery, 123(2), 151-156. https://doi.org/10.1016/S0039-6060(98)70252-1

Flemming, S., Hankir, M., Ernestus, R.-I., Seyfried, F., Germer, C.-T., Meybohm, P., ... Wiegering, A. (2020). Surgery in times of COVID-19-recommendations for hospital and patient management. Langenbeck's Archives of Surgery, 405, 359-364. https://doi.org/10.1007/s00423-020-01888-x

Fowler, D. L., \& Hogle, N. (2000). The impact of a full-time director of minimally invasive surgery. Surgical Endoscopy, 14(5), 444-447. https://doi.org/10.1007/s004640000158

Gillespie, B. M., Gwinner, K., Chaboyer, W., \& Fairweather, N. (2013). Team communications in surgery - creating a culture of safety. Journal of Interprofessional Care, 27(5), 387-393. https://doi.org/10.3109/13561820.2013.784243

González-Busto, B., \& García, R. (1999). Waiting lists in Spanish public hospitals: A system dynamics approach. System Dynamics Review, 15, 201-224. https://doi.org/10.1002/(SICI)1099-1727(199923)15:3<201::AID-SDR170>3.0.CO;2-5

Harnoss, J. C., Assadian, O., Diener, M. K., Müller, T., Baguhl, R., Dettenkofer, M., ... Kramer, A. (2017). Microbial Load in Septic and Aseptic Procedure Rooms. Deutsches Arzteblatt International, 114(27-28), 465-475. https://doi.org/10.3238/arztebl.2017.0465

Hau, T. (1999). Hierarchy in surgery in the United States. Zentralblatt fur Chirurgie, 124(3), $9-11$.

Kaye, D., Urman, R., \& Fox, C. (2019). Operating Room Leadership and Perioperative Practice Management. Cambridge: Cambridge University Press. 
https://doi.org/10.1017/9781108178402

Kazemier, G. (2006). A master surgical scheduling approach for cyclic scheduling in operating room departments. OR Spectrum, 30(2), 355-374. https://doi.org/10.1007/s00291-006-0068-x

Kojouri, K. (2004). Splenectomy for adult patients with idiopathic thrombocytopenic purpura: a systematic review to assess long-term platelet count responses, prediction of response, and surgical complications. Blood, 104(9), 2623-2634. https://doi.org/10.1182/blood-2004-03-1168

Lamiri, M., Xie, X., Dolgui, A., \& Grimaud, F. (2008). A stochastic model for operating room planning with elective and emergency demand for surgery. European Journal of Operational Research, 185(3), 1026-1037. https://doi.org/10.1016/j.ejor.2006.02.057

Marjamaa, R., Vakkuri, A., \& Kirvelä, O. (2008). Operating room management: Why, how and by whom? Acta Anaesthesiologica Scandinavica, 52(5), 596-600. https://doi.org/10.1111/j.1399-6576.2008.01618.x

May, J. H., Spangler, W. E., Strum, D. P., \& Vargas, L. G. (2011). The surgical scheduling problem: Current research and future opportunities. Production and Operations Management, 20,392-405. https://doi.org/10.1111/j.1937-5956.2011.01221.x

Mistry, P. K., Gaunay, G. S., \& Hoenig, D. M. (2017). Prediction of surgical complications in the elderly: Can we improve outcomes? Asian Journal of Urology, 4(1), 44-49. https://doi.org/10.1016/j.ajur.2016.07.001

Molina-Pariente, J. M., Fernandez-Viagas, V., \& Framinan, J. M. (2015). Integrated operating room planning and scheduling problem with assistant surgeon dependent surgery durations. Computers \& Industrial Engineering, 82, 8-20. https://doi.org/10.1016/j.cie.2015.01.006

Moorthy, K., Munz, Y., Forrest, D., Pandey, V., Undre, S., Vincent, C., \& Darzi, A. (2006). Surgical Crisis Management Skills Training and Assessment. Annals of Surgery, 244(1), 139-147. https://doi.org/10.1097/01.sla.0000217618.30744.61

Muhr G. (1999). Hierarchy in surgery. An antiquated system? Zentralblatt fur Chirurgie, $124(3), 2-5$.

Mulholland, M., \& Doherty, G. (2006). Complications in Surgery. UK: Lippinkot Publications. https://doi.org/10.1097/01.shk.0000245021.08988.da

Neumayer, L. A., Cochran, A., Melby, S., Foy, H. M., \& Wallack, M. K. (2002). The State of General Surgery Residency in the United States. Archives of Surgery, 137(11). https://doi.org/10.1001/archsurg.137.11.1262

Norman, G. R., Grierson, L. E. M., Sherbino, J., Hamstra, S. J., Schmidt, H. G., \& Mamede, S. (2018). Expertise in medicine and surgery. In K. A. Ericsson, R. R. Hoffman, A. Kozbelt \& A. M. Williams (Eds.), Cambridge handbooks in psychology. The Cambridge handbook of expertise and expert performance (pp. 331-355). Cambridge University Press. 
https://doi.org/10.1017/9781316480748.019

Persson, M., \& Persson, J. A. (2009). Health economic modeling to support surgery management at a Swedish hospital. Omega, 37(4), 853-863. https://doi.org/10.1016/j.omega.2008.05.007

Pories, S. E., Turner, P. L., Greenberg, C. C., Babu, M. A., \& Parangi, S. (2018). Leadership in American Surgery. Annals of Surgery, 1.

Puri, P., \& Höllwarth, E. (2009). Pediatric Surgery: Diagnosis and Management. UK: Springer. https://doi.org/10.1007/978-3-540-69560-8

Rezk, F., Stenmarker, M., \& Acosta, S. (2021). Healthcare professionals' experiences of being observed regarding hygiene routines: the Hawthorne effect in vascular surgery. BMC Infect Dis, 21, 420. https://doi.org/10.1186/s12879-021-06097-5

Saluja, S., Nwomeh, B., Finlayson, S. R. G., Holterman, A. L., Jawa, R. S., Jayaraman, S., \& Shrime, M. G. (2018). Guide to research in academic global surgery: A statement of the Society of University Surgeons Global Academic Surgery Committee. Surgery, 163(2), 463-466. https://doi.org/10.1016/j.surg.2017.10.013

Sidhu, R., Grober, E., Musselman, L., \& Reznick, R. (2004). Assessing competency in surgery: Where to begin? Surgery, 135(1), 6-20. https://doi.org/10.1016/S0039-6060(03)00154-5

Small, N. C. (1988). Complications in arthroscopic surgery performed by experienced arthroscopists. Arthroscopy: The Journal of Arthroscopic \& Related Surgery, 4(3), 215-221. https://doi.org/10.1016/S0749-8063(88)80030-6

Suman, G., \& Prajapati, D. (2018). Control chart applications in healthcare: A literature review. International Journal of Metrology and Quality Engineering, 9, 5. https://doi.org/10.1051/ijmqe/2018003

Sumpio, B. E., Armstrong, D. G., Lavery, L. A., \& Andros, G. (2010). The role of interdisciplinary team approach in the management of the diabetic foot. Journal of Vascular Surgery, 51(6), 1504-1506. https://doi.org/10.1016/j.jvs.2010.04.010

Swenne, C., \& Alexandrén, K. (2012). Surgical team members' compliance with and knowledge of basic hand hygiene guidelines and intraoperative hygiene. Journal of Infection Prevention, 13(4), 114-119. https://doi.org/10.1177/1757177412448407

Tabak, N., \& Orit, K. (2007). Relationship between how nurses resolve their conflicts with doctors, their stress and job satisfaction. Journal of Nursing Management, 15(3), 321-331. https://doi.org/10.1111/j.1365-2834.2007.00665.x

Terranova, L., Busetto, L., Vestri, A., \& Zappa, M. A. (2012). Bariatric Surgery: Cost-Effectiveness and Budget Impact. Obesity Surgery, 22(4), 646-653. https://doi.org/10.1007/s11695-012-0608-1

Tsue, T. T., Dugan, J. W., \& Burkey, B. (2007). Assessment of Surgical Competency. 


\section{Macrothink}

International Journal of Social Science Research

ISSN 2327-5510 2022, Vol. 10, No. 1

Otolaryngologic Clinics of North America, 40(6), 1237-1259. https://doi.org/10.1016/j.otc.2007.07.005

Van Oostrum, J. M., Van Houdenhoven, M., Hurink, J. L., Hans, E. W., Wullink, G., Xiang, W., ... Lim, G. (2015). An ant colony optimization approach for solving an operating room surgery scheduling problem. Computers \& Industrial Engineering, 85, 335-345. https://doi.org/10.1016/j.cie.2015.04.010

Yule, S., Flin, R., Paterson-Brown, S., \& Maran, N. (2006). Non-technical skills for surgeons in the operating room: A review of the literature. Surgery, 139(2), 140-149. https://doi.org/10.1016/j.surg.2005.06.017

\section{Copyrights}

Copyright for this article is retained by the author(s), with first publication rights granted to the journal.

This is an open-access article distributed under the terms and conditions of the Creative Commons Attribution license (http://creativecommons.org/licenses/by/4.0/). 